\title{
Quantitative chemo-biology: a chemical paradigm to understand biological phenomena*
}

\author{
Otto R. Gottlieb* and Maria Renata de M. B. Borin \\ Programa de Pós-Graduação em Química Orgânica, Instituto de Química, Universidade \\ Federal Fluminense, Campus do Valonguinho, 24020-005, Centro, Niterói, RJ, Brazil \\ E-mail:ogottlieb@abc.org.br
}

Dedicated to Professor Edmundo A. Rúveda on his $70^{\text {th }}$ birthday

(received 09 Aug 03; accepted 30 Sep 03; published on the web 04 Oct 03)

\begin{abstract}
While Physical Chemistry arose as a multidisciplinary approach necessary to describe matter, Chemo-Biology became a novel interdisciplinary effort to understand life. However, this endeavour requires integrating chemical (structural) and biological (functional) information in a "coherent language". As a consequence, general rules should emerge allowing introspections into questions about the functioning and understanding of nature and our attempt is overviewed in this paper.
\end{abstract}

Keywords: Angiosperms, natural products, molecular language, evolutionary rules, biodiversity, antagonism

\section{Introduction}

The ecologist Paul Ehrlich alerted: "Nothing is more important to human beings today than understanding how nature works." But, what do we mean by "understanding something"? The physicist Richard Feynman suggested that: "We can imagine that this complicated array of moving things which constitutes "the world" is something like a chess game being played by the gods, and we are observers of the game. We do not know what the rules of the game are. Of course, if we watch long enough, we may eventually catch on to a few of the rules, and consider that we understand the world. The most interesting phenomena are in the new places, the places where the rules do not work. That is the way in which we discover new rules!"

Following the discovery of the fundamental building blocks of organisms, molecular biologists were looking for the rules of functioning of life in the macromolecular machinery. However, in spite of enormous efforts, this did not help them either to understand the origin of life and of the species, or the evolution and the integration of the organisms. Even the question of 
Erwin Schrödinger of sixty years ago, "What is life?", still remains without answer. Why? Because genes are not equivalent to organisms. Organisms are dynamic systems subject to selective rhythms and, therefore, can not be reduced to the properties of an unique type of information, e. g. their genetic code.

General rules applied to any biological system only would emerge if different types of information, intrinsic and extrinsic to the organisms, was considered. Our efforts in this sense are overviewed in this paper showing some concepts capable to discuss fundamental questions about the functioning of nature and life.

\section{Life: What is it?}

Life is the result of revealed (genotype) and created (phenotype) information in sequence starting from molecules and organisms up to emotions and biomes (Figure 1). The interaction between these types of information leads to the opinion that micromolecules constitute the language responsible for the connectivity between organism and environment. Thus, small molecules are important starting points to begin understand life!

\section{LIFE $=\underbrace{\text { BIOMES }}_{\text {MOLECULES }} \begin{gathered}\text { created } \\ \text { INEaled }\end{gathered}$}

Figure 1. Definition of life as expression of revealed (inheritance) and created (evolutionary novelty) information in different organizational levels, from molecules to biomes. Adapted from de Loof.

According to Kornberg "much of life can be understood in rational terms if expressed in the language of chemistry. Unfortunately, the full use of this language to understand life processes is hindered by a gulf that separates chemistry from biology. Yet, chemistry and biology are two distinctive cultures and the rift between them is serious, generally unappreciated, and counterproductive." ${ }^{5}$ But, after all, the causes of biological phenomena are due to their diverse chemical arsenal. Thus, for us "understanding something", including "how nature works", means decoding the chemo-biological signs. However, how can chemistry and biology be unified? 


\section{Chemo-Biology: What is it?}

Only a "coherent language" can achieve the integration of chemical (structural) and biological (functional) terms capable of constructing a model to be used as a guide for the comparison of the properties of organisms. Thus, our major challenge consists in the replacement of the traditional and narrative approach, by a holistic and quantitative methodology.

The manifestation of life comprises at least three basic levels of organization: metabolism, morphology and biogeography (Figure 2). Evidence for correlations among these levels would be of fundamental importance, suggesting rules for the functioning of living organisms. To explore their connectivity, some prerequisites must be fulfilled:

- First, and most importantly, each level must be amenable to quantitative measurement by suitable parameters.

- Second, the mechanisms responsible for the integration among the respective levels should be recognizable. These levels are connected through the interface boundaries, membranes (and cell walls) at the metabolic and the morphologic levels and ecotones at the biogeographical level.

Our arguments are based on codification of data derived from flowering plants. But why flowering plants?

- First, angiosperms dominate most land areas of the present world in an astonishing variety of form and function. Their conservation and successful exploitation closely affected the fortunes and future of humanity.

- Second, with more than 250,000 species, angiosperms easily exceed the numbers of all other groups of plants taken together. And Brazil, with more than 55,000 species, exceeds in number of species all other countries.

- Last but not least, the third reason why flowering plants constitute a significant model systems for our investigations is based on their extraordinarily large number of natural products.

This point, leads to another basic question:

\section{Natural Products: What are they?}

But, what are natural products? Why plants produce an incredible abundance of these substances? Would it be to attract pollinators? Or, would they be defensive agents? Experts have suggested at least ten biological functions for these compounds e.g. metal-transporting agents, responsible for symbiosis interactions, products of "selfish" DNA, etc. ${ }^{7}$ It is incredible that no precise definition about natural products is yet available! 


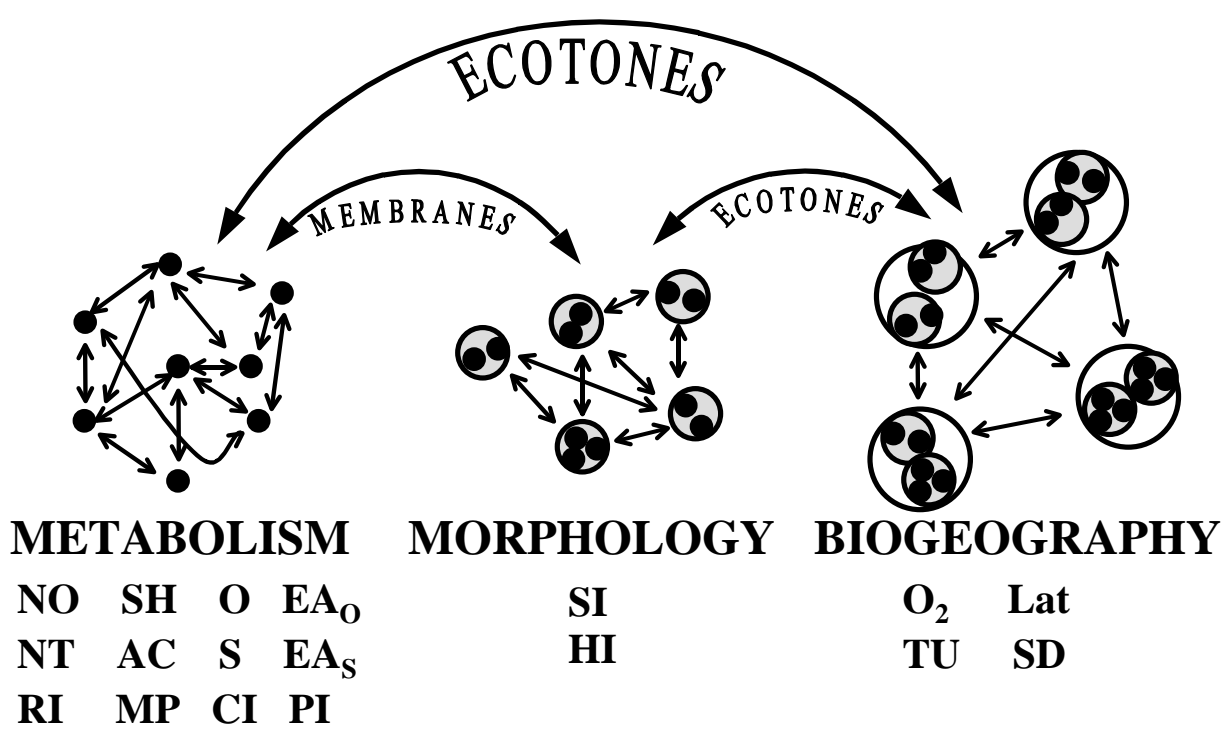

Figure 2. Angiosperm network - Diagram illustrating the connectivity among three organizational levels of angiosperms through quantitative parameters: Metabolic codes: NO number of occurrences (number of compounds of a biosynthetic category registered for each species of a taxon); NT number of structural types of compounds; RI relative importance index $(\mathrm{RI}=\mathrm{NT} \times \mathrm{NO})$; $\mathrm{SH}$ and $\mathrm{AC}$ resp. percentage of shikimate and acetate derivatives with relation to total number of compounds; MP metabolic profiles for a selected micromolecular category per region; $\mathrm{O}$ and $\mathrm{S}$ resp. oxidation and skeleton specialization states of a compound; $\mathrm{CI}$ evolutionary precedence-oriented chemical index; $\mathrm{EA}_{\mathrm{O}}$ and $\mathrm{EA}$ S resp. evolutionary advancement of a taxon according to oxidation and skeleton specialization states of their molecules; PI protection index (substituted vs. free phenolic hydroxyls); Morphologic codes: SI Sporne index (morphological advancement in angiosperm families); ${ }^{8} \mathrm{HI}$ herbaceousness index (decreasing lignin content); Biogeographic codes: $\mathrm{O}_{2}$ atmospheric oxygen level; TU taxonomic uniqueness of a region (index of biodiversity); Lat latitude; SD species dominance of a family per region.

However, for us, the primordial function of micromolecules in organisms, and probably the reason for their original appearance, does not concern attraction or defense but membrane construction. Life could not have started before the establishment of the first ionic/electric gradient, by a bordering membrane. The primordial organic material required protection by prebiotic vesicles and later by biotic membranes. ${ }^{4}$ Cellular membranes possess polar surfaces and lipophilic interiors due to the concurrence of steroids and polyunsaturated fatty acids, support electron flow ${ }^{14}$ via an ubiquinone pool, promote nutrient-product exchange via specific protein channels, establish concentration gradients via tridimensional barriers, support enzymatic proteins for the synthesis of chemical signals (codes). Such phenomena justify the structural variation of protein-catalysed micromolecular products. Thus, membranes are conditions sine qua non for the existence of secondary metabolism. For this reason most metabolites exist in 
plants, fungi, segmented insects and porous sponges; while, in contrast, only few natural products occur in animals exempt of cell walls. Hence, from the structural point of view: Natural products $\underset{9,15,16}{\operatorname{most}}$ probably waste products of the optimisation procedure of membrane construction.

However, considering the principal properties of micromolecules, small molecular mass, polarity, chirality, chemical reactivity (structural variation), different and variable half-lifes, sporadic occurrence and antioxidant potential; it is possible to suggest that these molecules are messengers of information. The existence of messengers and of antioxidants is indispensable requirement for the functioning of the cellular machinery, from the point of view of synchronisation of its parts, as well as the stability in face of certain factors of stress, e.g. water and oxygen. Indeed, in accord with our oldest chemical definition, life is the dispute for and against water, for and against oxygen!

The plant cell is a polygenomic system with perhaps four macromolecular complexes composed of deoxyribonucleic and ribonucleic acids and a group of enzymes. In order that these complexes should function in perfect synchronisation and harmony, as indeed it happens, they must be integrated via fluxes of information. ${ }^{17}$ Operated by micromolecules such fluxes insert the compartimentalised systems in an "autocatalytic" cycle of reactions, a hypercycle (Figure 3 ). Compartimentalisation and hypercycles are two complementary organisational principles offering the necessary evolutionary stability to the system.

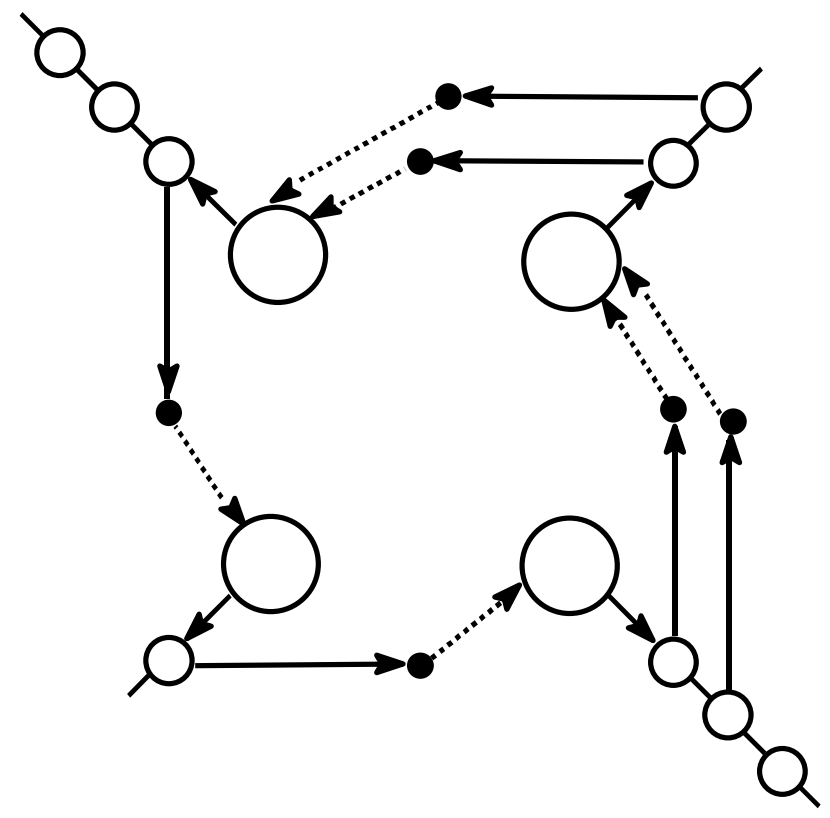

Figure 3. Schematic diagram of a tetragenomic plant cell demonstrating the direct transduction of signals (solid arrows) of genomes (larger circles) to proteins (intermediate circles), and the indirect transduction (dashed arrows) among genomes, mediated by special metabolites (solid circles). Based on the hypercycle concept of Eigen. 
From the functional point of view: Natural products are words of the evolutionary-ecological language, responsible for the existence, synchronisation and modulations of the energy and information of the plant metabolic webs ("self-organisation" and "self-regulation"). If micromolecules are words of language, what are the rules of this language? What are the mechanisms regulating the metabolic evolution? How does micromolecular metabolism operate?

\section{Molecular language: What are its grammatical rules?}

\section{- Temporal (Functional evolutionary) Redox Potential}

We demonstrated that in angiosperms, diversification within each metabolic category involves a gradually increasing oxidation value of the corresponding metabolites. ${ }^{19}$ These chemical lineages accompany morphological sequences, recognised via evolutionary indices (HI, SI). Thus, oxidation/reduction cascades may constitute an example of antagonistic oscillations of natural products. Variation of the redox potential, responsible for metabolic diversification, is the controlling force of the micromolecular evolution and operates through the increase of oxidative steps.

\section{Evolutionary canalization}

Our integrative chemo-biological approach allows the reconstruction of the evolutionary history of modern plants through chemical compounds. In the plant metabolic cycle, atmospheric $\mathrm{CO}_{2}$ is reduced in the photosynthetic cycle (Calvin cycle) to carbohydrates, precursors of shikimic and acetic acids. Thus, a biosynthetic scheme of intermediate metabolism indicates the branching points, either on the shikimate route or on the acetate route, which lead to the different categories of natural products. Impact of both pathways generates products of mixed biosynthesis, such as flavonoids and stilbenoids. Quantitative analysis of the diversification of natural products suggests that in angiosperms, micromolecular evolution operates through replacement of the shikimate pathway by the acetate/mevalonate pathway, in a process designated evolutionary canalization. ${ }^{20}$ These results indicate that:

- Plant metabolism forms a dynamic network comprising shikimate and acetate derived processes, synchronized and regulated by activation/inhibition (antagonistic oscillations) of the biosynthetic reactions.

- Gallic and caffeic acids, functioning as a dualistic pair, plays a decisive regulatory role in this evolutionary history, ${ }^{15,21}$ inhibiting the dissipation of energy and the collapse of the metabolic network.

\section{- Spatial (Structural ecological)}


At this point, it becomes necessary to raise a relevant question: What is the significance of these basic concepts for the poorest population living within one of the most important biological boundaries on Earth, the Brazilian Amazonia?

Human wellbeing requires expertise in biodiversity. But, are there patterns to biodiversity? Unfortunately, biodiversity, in the present descriptive stage, fails to answer three fundamental questions, prerequisites to any practical application: Biodivertsity: Where is it? Why it is there? What will it become? ${ }^{10}$ Investigations in Brazil suggest that mechanistic explanations of biological phenomena would not reach success if it were based only on behaviour or on form. It is necessary to consider that generally their cause is chemistry.

A Brazilian map of vegetation elaborated 1993 by IBGE (Fundação Instituto Brasileiro de Geografia e Estatística) shows the $8,500,000 \mathrm{~km}^{2}$ of territory classified into nine phytoecological regions, such as the Amazonian rain forest, caatinga, cerrado, Atlantic forest, Araucaria forest, etc. Additionally, the map indicates three vegetation areas, including areas of ecological tensions limiting ecosystems, defined as encraves and ecotones. The diversity of these edge biomes attests for their generality as models in the study of mutual interactions of ecosystems and their respective mechanisms.

\section{Creativity of Geographic Interfaces (Ecotones):}

Are there regulatory mechanisms of spatial radiation of organisms?

Ecotones, such as membranes, possess creativity and polarity, directing migratory fluxes of organisms, hindering homogenization and increasing biodiversity. These geographic areas serve as "natural corridors" for each ecosystem. ${ }^{11,22}$ This is another important and general concept applicable to different organisms and systems. "Until now conservationists have focused on preserving blocks of rainforest, but they have paid little attention to the ragged forest border." 23

\section{Bioconnectivity}

Are there integrated plant webs?

Quantitative comparison of the floristic composition of 76 plant inventories, allows the pairwise determination of degrees of similarity of these different neotropical biomes. The resulting plot confirms affinity of northern biomes (Amazonian forests) with all other biomes to diminish in the southern direction, and affinity of southern biomes (Patagonian steppes) with all other biomes to diminish in the northern direction. However, central biomes ("cerrados") show significant affinities with northern, eastern and southern biomes. Additionally, it is important to note that the ecotones display greater similarity with all habitats than their respective ecosystems $^{12,22}$. Hence, these findings demonstrate: Neotropical ecosystems, linked by ecotones, to form integrated plant webs in central Brazil.

\section{Antagonism: A unifying concept?}


Now, we would "dare" ask a final question: Are there general evolutionary-ecological mechanisms operating in different systems?

Providing experimental evidence based on natural products, we then perceived the importance of dualistic systems in all phenomena. Some of these pairs were detected in the present work, e.g. shikimate/acetate pathways, gallic/caffeic acids, forest/cerrado, ecosystems/ecotones. Our results indicated that these dualistic systems, jointly with a wide range of physical, chemical, biological, and social systems, offer the ecological plasticity indispensable for adaptations to environmental changes. Thus, Quantitative Chemo-Biology reveals modulation of opposing features as the fundamental mechanism of evolutionary-ecology, and the concept should possess universal relevance. Antagonism is not only an evolutionary principle ruling angiosperms, but also operates in many universal systems, from molecules to universe.

\section{Conclusions}

Science in this new millennium will have to be prepared to answer questions concerning how nature works. This goal will be achieved following the concept of a chemo-biological language, rather than by a reductionist approach. However, the obstinate efforts of our group to understand the mechanisms of nature through a chemo-biological language, has already been considered "only a dream" by some. Others consider that the objectives of phytochemistry in developing countries should be restricted to the search for bioactive compounds. Such opinions make any attempt of rational interference in nature, mere philosophic and demagogic exercises. It is impossible to act rationally in a system ignoring the mechanism of its functioning!

\section{Acknowledgments}

Supported by a grant from Academia Brasileira de Ciências, Rio de Janeiro, Fundação Carlos Chagas Filho de Amparo à Pesquisa do Estado do Rio de Janeiro, Rio de Janeiro and Conselho Nacional de Desenvolvimento Científico e Tecnológico, Brasília, Brazil. 


\section{References and Notes}

* Based on a lecture presented on the Workshop "New Concepts and Applications of Physical Organic Chemistry", Universidade Federal Fluminense, Niterói, RJ, Brazil, October 21, 2002.

1. 1Ehrlich, P. R. The Machinery of Nature - The Living World Around Us and How It Works, Simon \& Schuster, Inc.: New York, 1986; p 12.

2. Feynman, R. P.; Leighton, R. B.; Sands, M. The Feynman Lectures on Physics, AddisonWesley Publishing Company, Reading, sixth printing, 1977, Volume I, p 2-1.

3. Schrödinger, E. What is Life? The Physical Aspect of the Living Cell, Cambridge University Press, Cambridge, 1944.

4. Loof, A. de Int. J. Biochem. 1993, 25, 1715.

5. Kornberg, A. Biochemistry 1987, 26, 6888.

6. Hughes, N. F. The Enigma of Angiosperm Origins, Cambridge University Press: Cambridge, 1994, p 1.

7. Davies, J. In: Secondary Metabolites: Their Function and Evolution, Chadwick, D. J.; Davies, J.; John Wiley \& Sons Ltd: Chicester, England, 1992, p 1

8. Sporne, K. R. New Phytol. 1980, 85, 419.

9. Gottlieb, O. R.; Kaplan, M. A. C.; Borin, M. R. de M. B. Biodiversidade. Um Enfoque Químico-Biológico, Editora UFRJ, Rio de Janeiro, 1996, p 267. Gottlieb, O. R.; Kaplan, M. A. C.; Borin, M. R. de M. B. Biodiversidad: Un Enfoque integrado entre la Química y la Biologia, Versión castellana de Alicia B. Pomilio, Artes Gráficas Buschi S.A.: Buenos Aires, Argentina, 2001, p 239.

10. Gottlieb, O. R.; Borin, M. R. de M. B. An. Acad. Bras. Ci. 1994, 66, 55.

11. (a) Gottlieb, O. R.; Borin, M. R. de M. B. In: Freitas, M. de L. D. de Amazonia: Heaven of a New World, Editora Campus: Rio de Janeiro, 1998, p 71. (b) Gottlieb, O. R.; Borin, M. R. de M. B. In: Freitas, M. de L. D. de Amazonien: Himmel der Neuen Welt. Eine Sammlung von Essays und wissenschaftlichen Beiträgen über das brasilianische Amazonasgebiet, Bonn, 1999, p 75.

12. Gottlieb, O. R.; Borin, M. R. de M. B. An. Acad. Bras. Ci. 1999, 71, 157.

13. Gottlieb, O. R.; Borin, M. R. de M. B. Pure \& Appl. Chem. 1999, 71, 1635.

14. Koch, A. L. J. Theor. Biol. 1994, 168, 269.

15. Gottlieb, O. R.; Borin, M. R. de M. B.; Kaplan, M. A. C. Phytochemistry 1995, 40, 99.

16. 1 Gottlieb, O. R.; Borin, M. R. de M. B. An. Acad. Bras. Ci. 1998, 70, 719.

17. Sengbusch, P. von Botanik, McGraw-Hill Book Co., Hamburg 1989, p167.

18. (a) Eigen, M.; Schuster, P. Naturwissenschaften 1977, 64, 541. (b) Eigen, M. Stufen zum Leben: Die frühe Evolution im Visier der Molekularbiologie, Piper, München, 1987, p 225.

(c) Eigen, M.; Winkler-Oswatitsch, R. Steps Towards Life: A Perspective on Evolution, Oxford University Press, Oxford, 1992, p 107. 
19. 1(a) Gottlieb, O. R. Micromolecular Evolution, Systematics and Ecology. An Essay into a Novel Botanical Discipline, Springer Verlag, Berlin, 1982, p 170. (b) Gottlieb, O. R. Phytochemistry 1989, 28, 2545.

20. (a) Gottlieb, O. R. An. Acad. Bras. Ci. 1984, 56, 43. Kubitzki, K; Gottlieb, O. R. Taxon 1984, 33, 375. (b) Gottlieb, O. R. In: Rowe, J. W. Natural Products of Woody Plants: Chemicals Extraneous to the Lignocellulosic Cell Wall, Springer-Verlag, Berlin, 1989, chapter 3, p 125. Gottlieb, O. R.; Borin, M. R. de M. B. Mem. Inst. Oswaldo Cruz 2000, 95, 115.

21. Gottlieb, O. R.; Borin, M. R. de M. B. Phytochemistry 1998, 49, 1.

22. Gottlieb, O. R.; Borin, M. R. de M. B. Phytochemistry 2000, 55, 559.

23. Brown, K. New Scientist 1999, 46. 